\title{
Hot tensile deformation and fracture behavior of ultrafine-grained AZ31 magnesium alloy processed by severe plastic deformation
}

\author{
A. Fata, G. Faraji*, M.M. Mashhadi, V. Tavakkoli \\ School of Mechanical Engineering, College of Engineering, University of Tehran, Tehran 11155-4563, \\ Iran. \\ *Corresponding author, email: ghfaraji@ut.ac.ir, Tel/Fax: +982161119966.
}

\begin{abstract}
Parallel tubular channel angular pressing (PTCAP) process as a novel intense plastic deformation method was applied to an AZ31 magnesium alloy tubes to achieve an ultrafine grained (UFG) structure. Tensile tests at different temperatures of $25^{\circ} \mathrm{C}, 350^{\circ} \mathrm{C}, 400{ }^{\circ} \mathrm{C}$ and 450 ${ }^{\circ} \mathrm{C}$ were done on UFG AZ31 samples processed by multipass PTCAP process. The results showed that the second passes PTCAP processed specimen exhibits the best elongation of about $263 \%$ at a temperature of $400{ }^{\circ} \mathrm{C}$. Fractured tensile samples were metallurgically characterized to analyze the fracture mechanism. The result indicated a decreasing trend in the average grain size along the gripper section to failure tip of the fractured UFG sample. However, the hardness increases from gripper region to the end of gauge region near the fracture tip. However, at the fracture tip, hardness collapsed because the cavity and microvoids formed in this area during tensile deformation. Fractographic SEM images illustrated the mix ductile and brittle fracture modes at tensile temperatures of $350{ }^{\circ} \mathrm{C}$ and $450{ }^{\circ} \mathrm{C}$. Though, completely ductile fracture mode with distinguishable dimples was seen at the UFG sample fractured at $400{ }^{\circ} \mathrm{C}$.
\end{abstract}


Keywords: Ultrafine grained; AZ31 magnesium alloy; SPD; PTCAP; Hot deformation; Fracture.

\section{Introduction}

Among the different ways to reduce fuel consumption and exhaust emission of vehicles, reduction of mass is one of the most powerful and least costly methods. Magnesium and its alloys are the relatively lightest structural metals primarily used as structural alloys due to its light weight. They exhibit relatively high specific strength, good corrosion resistance, and machinability. Different structural applications of magnesium alloys are engine parts, aircraft fuselages, wheels, and digital device cases. They are also used in rockets, missiles, jet-engine parts, portable power tools, and luggage frames. Nevertheless, poor formability and low ductility of these alloys limit their usage [1]. As a result, many attempts have been performed to resolve these restrictions. Severe plastic deformation (SPD) capable of producing ultrafine grained (UFG) and nanograined metals is the main tool for the researcher to improve the formability of magnesium alloy $[2,3]$. UFG and nanograined metals show high strengths at room temperature and superplastic behavior at higher temperatures. Equal channel angular pressing (ECAP) [4-6], high-pressure torsion (HPT) [7-9] and accumulative roll bonding (ARB) [10-12] are the most famous of the SPD processes. Kang et al. applied ECAP process on a magnesium alloy AZ31 to investigate the effect of the process on its microstructure and mechanical properties [13]. They reported that the elongation to failure was increased with decreasing the grain size by ECAP processing at increased temperatures. Miyahara et al. studied the superplastic behavior of AZ61 magnesium alloy processed by a combination of extrusion and ECAP. They found that the alloy

exhibits exceptional superplastic properties with a maximum elongation of $1320 \%$ after 
processing by four passes of the combined process [14]. According to the broad industrial application of tubular components, new SPD methods are demanded to fabricate UFG and nanograined tubular specimens. Hence, Faraji et al. $[15,16]$ presented parallel tubular channel angular pressing (PTCAP) process in which a cylindrical tube is deformed to an extremely large strain without a change in its dimensions. As illustrated in Fig. 1(a), at the first half cycle of the PTCAP process, the tube constrained between the mandrel and die is extruded through the symmetric shear zones so that the diameter of the tube increased to a maximum value. At the second half cycle, the tube is returned to the initial dimension by extruding back to the same shear regions by the second hollow punch as shown in Fig. 1(b). The parameters of PTCAP process were also represented in Fig. 1. Different aspects of UFG tubes fabricated via PTCAP processes such as mechanical anisotropy [17], transmission electron microscopy analyzes and determination of dislocation density [18], and energy absorption capacity [19] were investigated by the researchers. Moreover, there are a few published data on the tubular SPD-processed magnesium alloys [20], and there is almost no published paper about the microstructure evolution of hot deformation and superplastic behavior of AZ31 tubes processed by PTCAP. In this study, hot deformation behavior of AZ31 magnesium alloy tubes processed via multipass PTCAP is investigated. Also, the influence of tensile test temperature on the microstructural evolution during the tensile test is examined. Moreover, the fracture mechanism of UFG AZ31 alloy tube during tensile loading at elevated temperatures is investigated. 


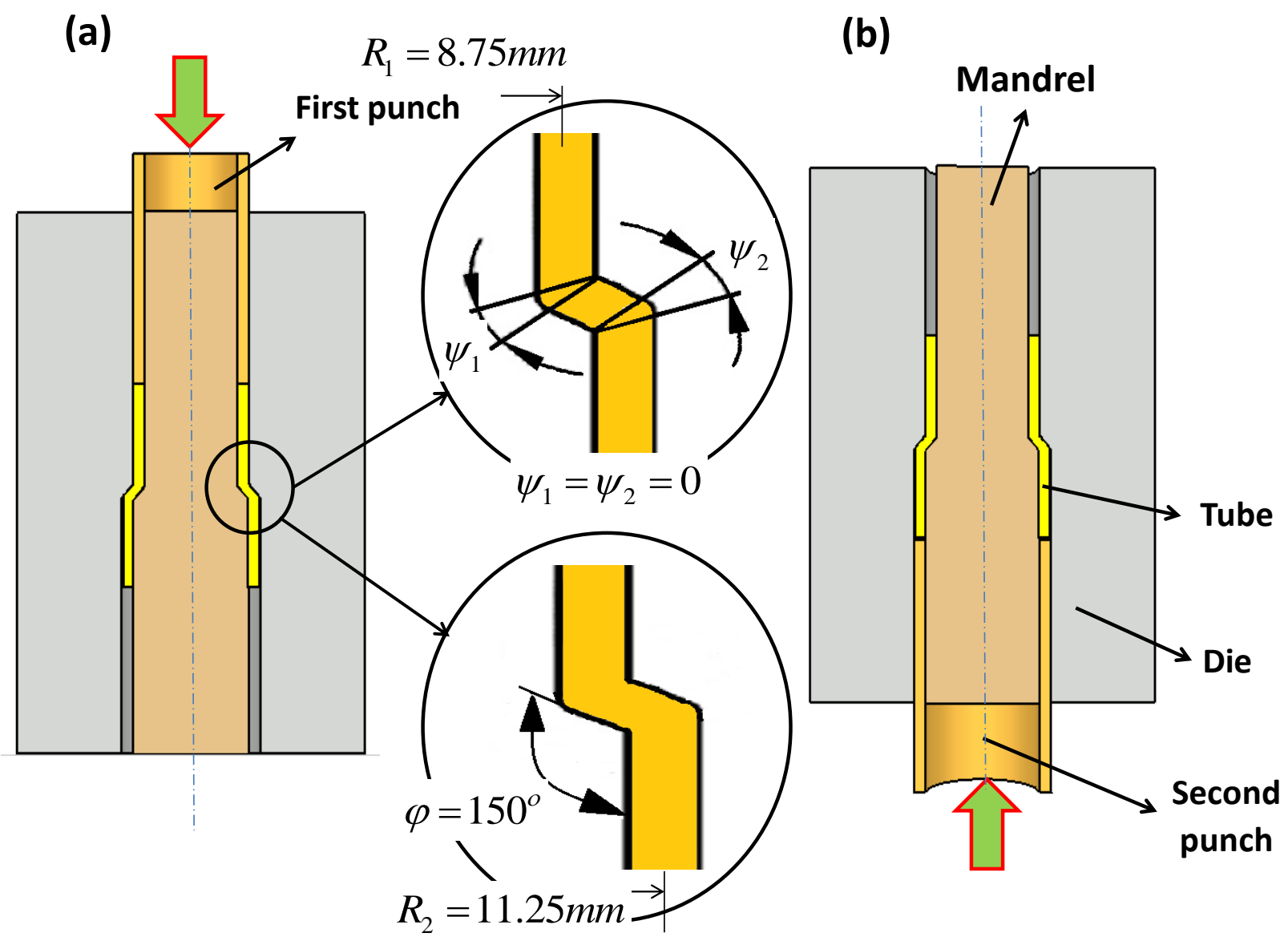

Fig. 1. Schematic of (a) the first half pass and (b) the second half pass of the PTCAP process along with the die parameters [21].

\section{Materials and Methods}

The experiments were conducted on an as-cast AZ31 magnesium alloy with a chemical composition shown in Table 1 . Samples in a tube form with an outer diameter of $20 \mathrm{~mm}$, a thickness of $2.5 \mathrm{~mm}$ and length of $40 \mathrm{~mm}$ were prepared from the as-cast ingot by machining. A PTCAP die was designed and manufactured from hot work steel (H13) and hardened up to 50 HRC. The PTCAP tests were performed through one, two and three passes by an INSTRON 
press machine at a temperature of $300{ }^{\circ} \mathrm{C}$ at a ram speed of $10 \mathrm{~mm} / \mathrm{min}$. Molybdenum disulfide $\left(\mathrm{MoS}_{2}\right)$ was applied as the lubricant to reduce the friction between contacting surface of dies and sample [21]. Mechanical properties and microstructural evolution of unprocessed and PTCAP processed tubes were characterized. The tensile test specimens with $4 \mathrm{~mm}$ in gage length lying parallel to the longitudinal axes of the tube with the cross-sectional area of $2.5 \times 3 \mathrm{~mm}^{2}$ were prepared using wire electro-discharge machining. First, the samples were tensile tested at a constant temperature $400{ }^{\circ} \mathrm{C}$ at a strain rate of $10^{-3} \mathrm{~s}^{-1}$ using an SANTAM tensile testing machine. Then, the tensile sample prepared from two passes PTCAP processed tube were tensile tested at different temperatures of $350{ }^{\circ} \mathrm{C}, 400{ }^{\circ} \mathrm{C}$, and $450{ }^{\circ} \mathrm{C}$. Three separate samples were tested for each experimental condition to warrant good reproducibility. Subsequently, the microstructures of tensile samples after the test were characterized using optical microscopy (OM) along the tensile loading. The samples were mechanically polished and then etched for $5 \mathrm{~s}$ using a solution of $4 \mathrm{~g}$ picric acid, $10 \mathrm{ml}$ acetic acid, $70 \mathrm{ml}$ ethanol, and $20 \mathrm{ml}$ distilled water. The fractured surface morphologies were observed by scanning electron microscopy (SEM) using a Hitachi-FESEM. Vickers microhardness tests were accomplished using COOPA model microhardness machine at a load of $200 \mathrm{~g}$ applied for $10 \mathrm{~s}$.

Table 1. The chemical composition of AZ31 magnesium alloy

\begin{tabular}{cccccccc}
\hline Element & $\mathrm{Al}$ & $\mathrm{Zn}$ & $\mathrm{Mn}$ & $\mathrm{Si}$ & $\mathrm{Fe}$ & $\mathrm{Cu}$ & $\mathrm{Mg}$ \\
\hline Mass $(\%)$ & 2.90 & 0.95 & 0.20 & 0.013 & 0.15 & 0.01 & Bal. \\
\hline
\end{tabular}




\section{Results}

Fig. 2 shows typical OM microstructure of as-received and PTCAP processed tubes after first, second and third passes. The homogeneous microstructure of the as-received material with a mean grain size of $\sim 520 \mu \mathrm{m}$ is observed in Fig. 2(a). Figs. 2(b-d) illustrate the microstructure of multipass PTCAP processed tubes. As shown, new finer grains formed along the initial grain boundaries. The necklace-like arrangement named bimodal structure in Figs. 2(b-d) was also observed in the previous studies $[22,23]$.

The influence of the number of PTCAP passes on the stress-strain curve of the AZ31 samples at an initial strain rate of $10^{-3} \mathrm{~s}^{-1}$ at a testing temperature of $400{ }^{\circ} \mathrm{C}$ is shown in Fig. 3. Inspection shows that the flow stress and ductility of the first and second pass PTCAP processed samples are higher than that of the as-received sample. Though, lower strength is seen for the third pass PTCAP processed sample. It is clear that the yield strength of the third pass processed sample decreases to $\sim 15 \mathrm{MPa}$ from an initial value of $\sim 45 \mathrm{MPa}$. As shown in Fig. 3, the second pass PTCAP processed sample exhibits $263 \%$ elongation to failure at $400{ }^{\circ} \mathrm{C}$. Therefore, to investigate the influence of temperature, second pass processed sample was selected to pull out at various temperatures of $350{ }^{\circ} \mathrm{C}, 400{ }^{\circ} \mathrm{C}$, and $450{ }^{\circ} \mathrm{C}$. 

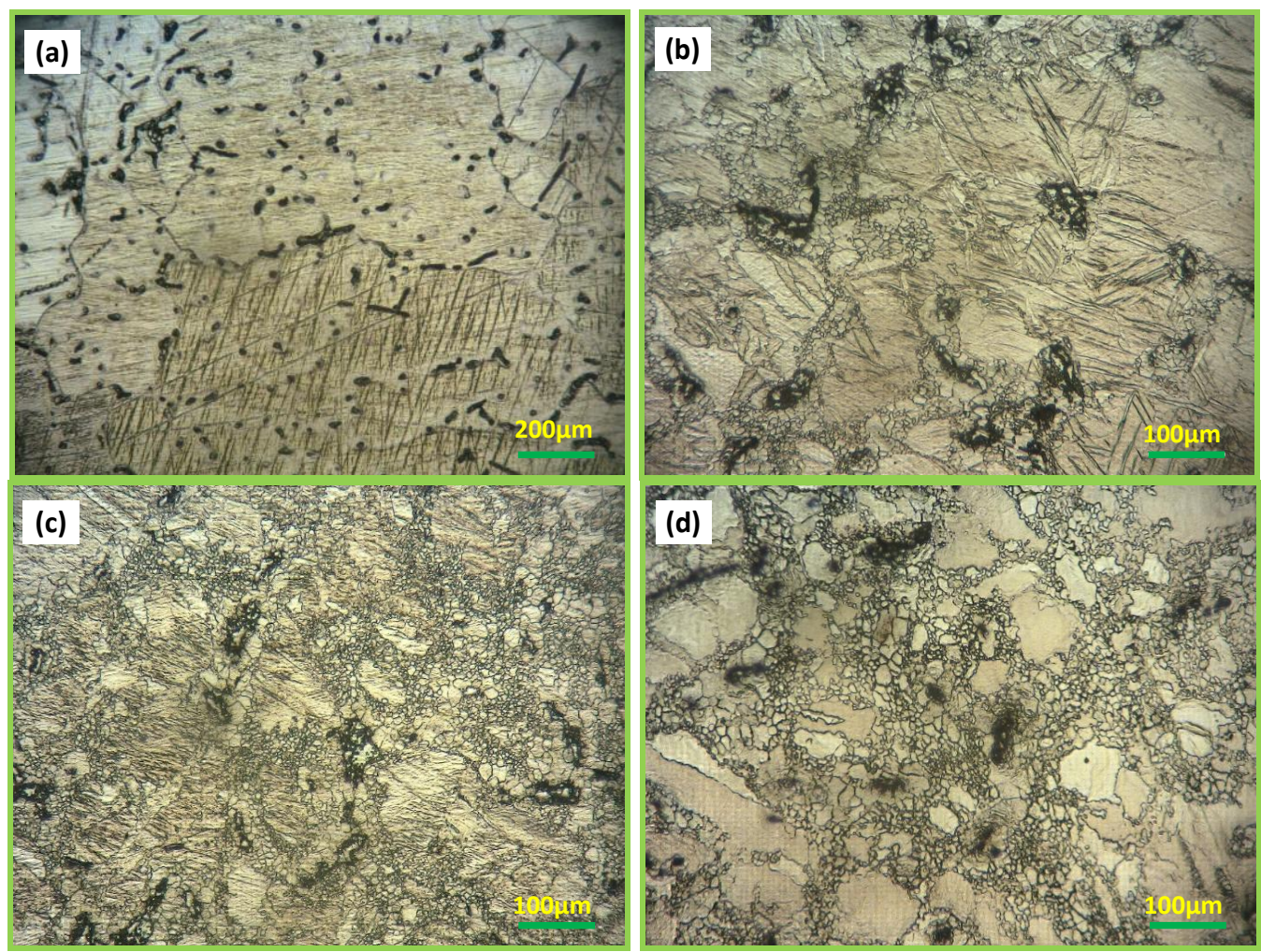

Fig. 2. OM microstructure of as received (a), and PTCAP processed tube through first (b),

second (c), and third (d) passes.

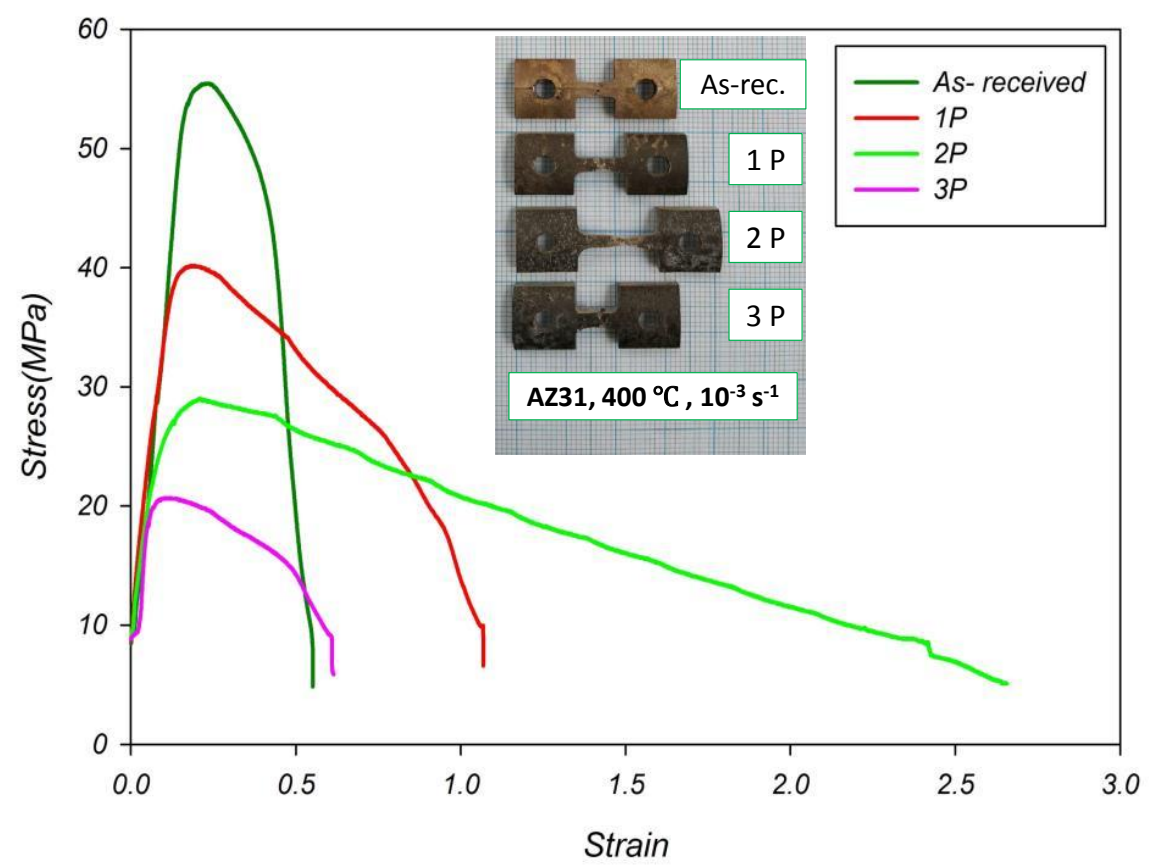

Fig. 3. Engineering stress-strain curves of as received and multipass PTCAP processed samples tested at $400{ }^{\circ} \mathrm{C}$ at an initial strain rate of $0.001 \mathrm{~s}^{-1}$. 
Fig. 4 shows engineering stress-strain curves of the second pass PTCAP processed sample tested at various temperatures at an initial strain rate of $0.001 \mathrm{~s}^{-1}$. As shown, the flow stress increases rapidly with increasing strain to reach a maximum value at the certain strain. Then, the flow stress continuously decreased in all curves. At the initial stage of the tensile test, the strain hardening occurred due to the accumulation of dislocations [24]. After peak stress, the softening behavior occurred due to the initiation of dynamic recrystallization and grain growth at elevated temperatures [25]. The highest strength is found at a temperature of $350{ }^{\circ} \mathrm{C}$, though the sample was rapidly fractured at a relatively low elongation of $\sim 79 \%$. In contrast, at $400{ }^{\circ} \mathrm{C}$, the sample reveals a more active dynamic process and the elongation reached to $263 \%$. Though, $50 \%$ lower peak strength is seen in comparison with $350{ }^{\circ} \mathrm{C}$ counterpart.

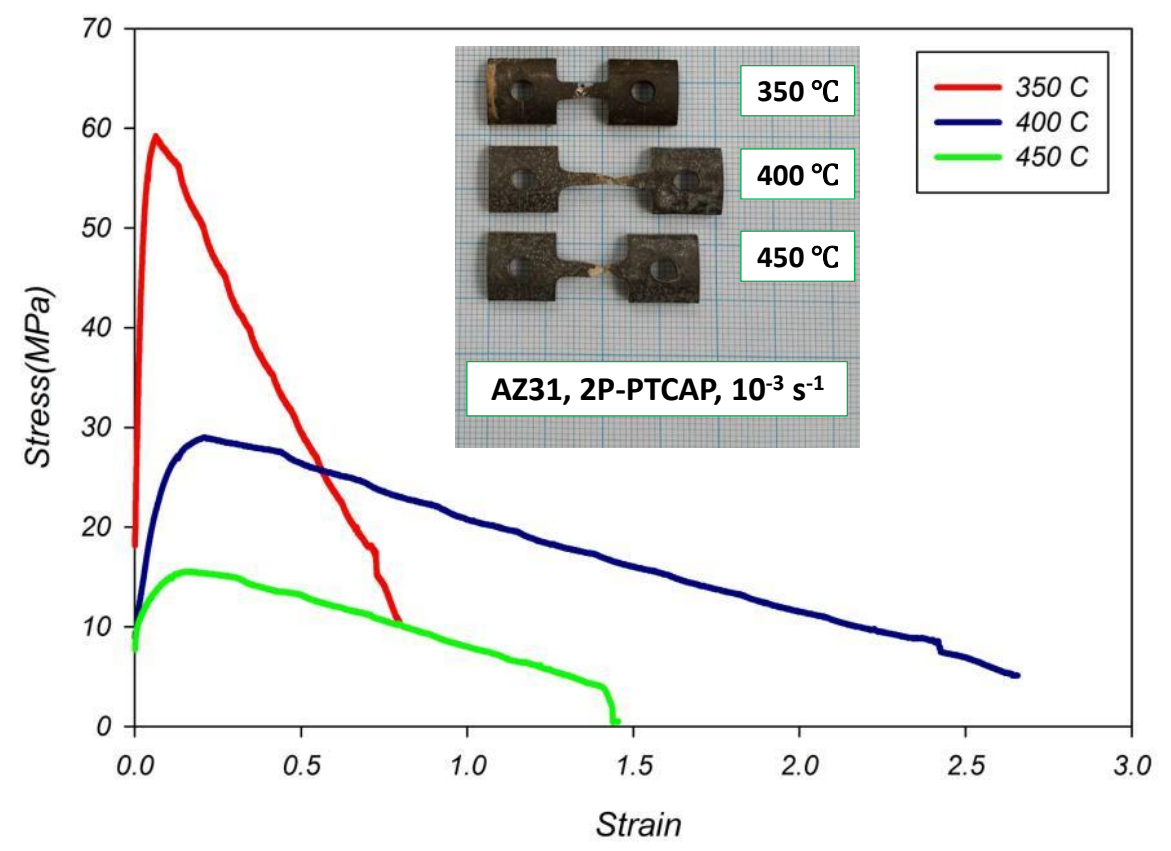

Fig. 4. Engineering stress-strain curves of second pass PTCAP processed at different temperatures at a strain rate of $0.001 \mathrm{~s}^{-1}$.

Figs. 5-7 show OM micrographs of the fractured tensile test of the second pass PTCAP processed samples at different regions (near the fracture tip, gripper region, and gauge regions) 
tested at a strain rate of $10^{-3} \mathrm{~s}^{-1}$ at $350{ }^{\circ} \mathrm{C}, 400{ }^{\circ} \mathrm{C}$ and $450{ }^{\circ} \mathrm{C}$, respectively. At elevated temperatures, the non-basal slip systems like pyramidal and prismatic slip become active. This leads to improvement in the ductility [26]. Nevertheless, some undesirable phenomena such as strain concentration and cavity formation can aggravate the ductility [27, 28]. Fig. 5 illustrates the $\mathrm{OM}$ microstructure of different positions of the tensile sample tested at $350{ }^{\circ} \mathrm{C}$. As it reveals, the bimodal structure remains with few rounded cavities in the fractured tip region. Fig. 6 exhibits the microstructures of the tensile specimen tested at $400{ }^{\circ} \mathrm{C}$. Fracture tip at $400{ }^{\circ} \mathrm{C}$ shows more necking with a wider range of elongated cavities size. The spread of cavity formation depends on three factors of nucleation, growth and inter-linkage [29-31].

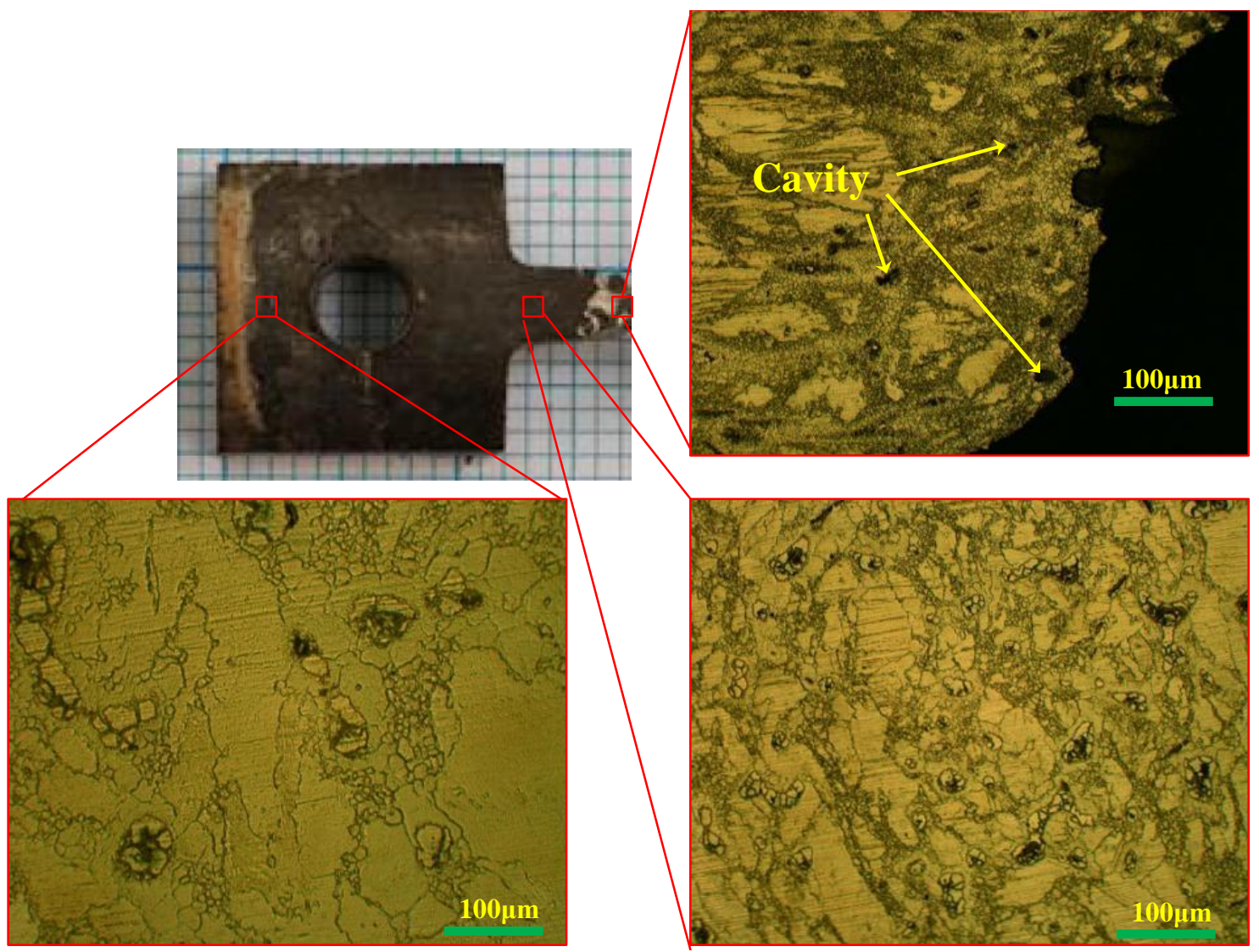

Fig. 5. OM microstructure of the various positions of the fractured tensile test sample (prepared from two passes PTCAPed sample) deformed at $350^{\circ} \mathrm{C}$. 


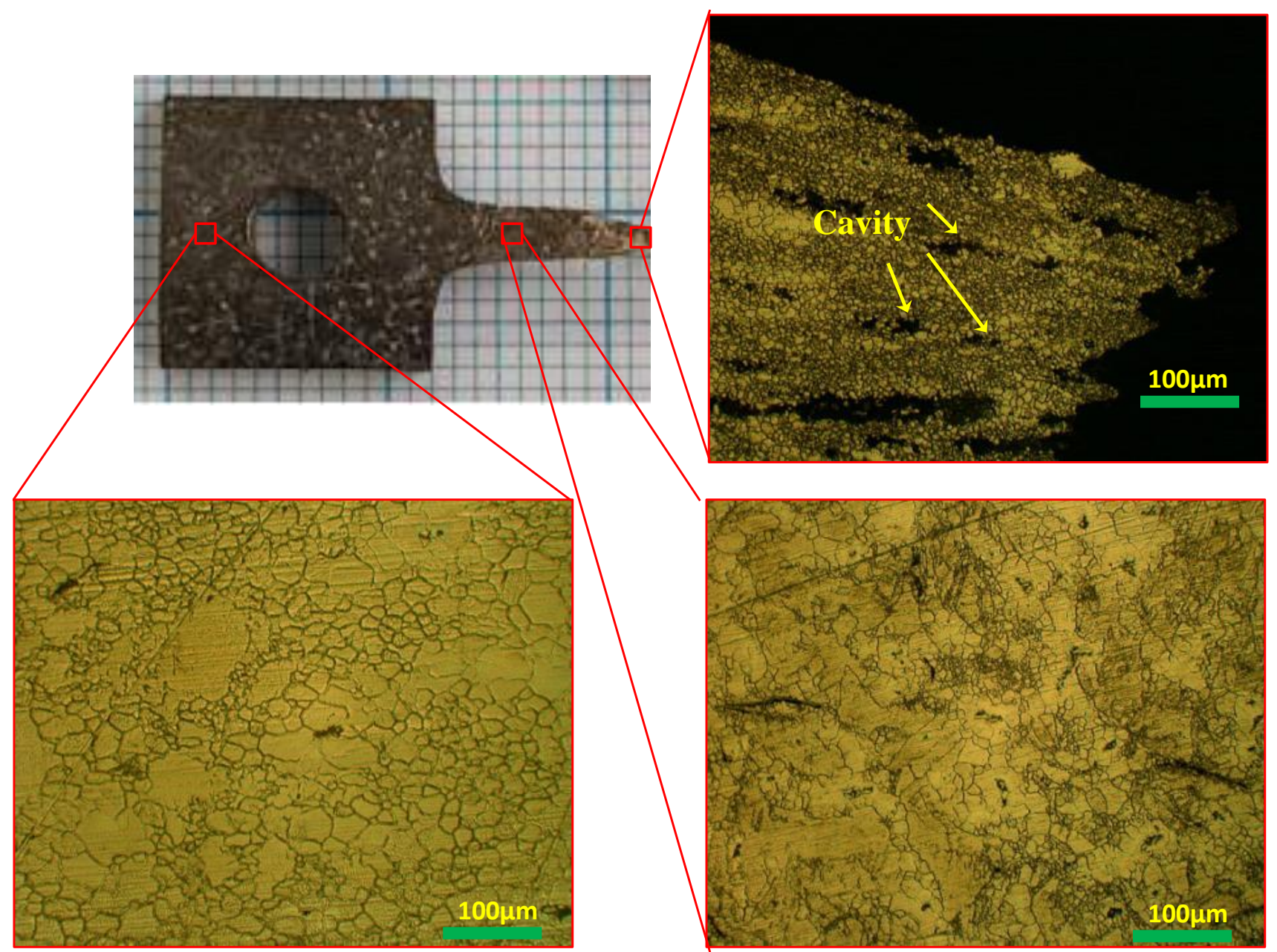

Fig. 6. The microstructure of various positions of the fractured tensile test sample (prepared from two passes PTCAPed sample) deformed at $400{ }^{\circ} \mathrm{C}$.

At a temperature of $450{ }^{\circ} \mathrm{C}$, as shown in Fig. 7, the recrystallized grains grow up and leads to a decrease of the strength. It also caused the average grains size to become $14 \mu \mathrm{m}$. It is widely known that DRX takes place by grain boundary diffusion and migration process [25]. The increase of the deformation temperature can strengthen the grain boundary diffusion and migration process which assist to activate the grain boundary sliding as a dominant deformation mechanism. The distinct bimodal structure was observed at a temperature of $350{ }^{\circ} \mathrm{C}$ in the gauge region, however in $400{ }^{\circ} \mathrm{C}$ sample, few fine grains was evident besides coarse grains. Though, almost equiaxed grains appear in the sample tested at $450{ }^{\circ} \mathrm{C}$ due to DRX. The microstructure of 
gripper sections is coarser than other positions in all samples due to static annealing and no straining.

Fig. 8 represents that the overall area of fracture tip region covered by cavities are $3.5 \%, 14 \%$, and $5 \%$ at various test temperatures of $350{ }^{\circ} \mathrm{C}, 400{ }^{\circ} \mathrm{C}$, and $450{ }^{\circ} \mathrm{C}$, respectively. It means that the density of cavities at $350{ }^{\circ} \mathrm{C}$ is smaller than others. Also, at $400{ }^{\circ} \mathrm{C}$, the density of cavities is largest, and the cavity shapes are almost irregular.

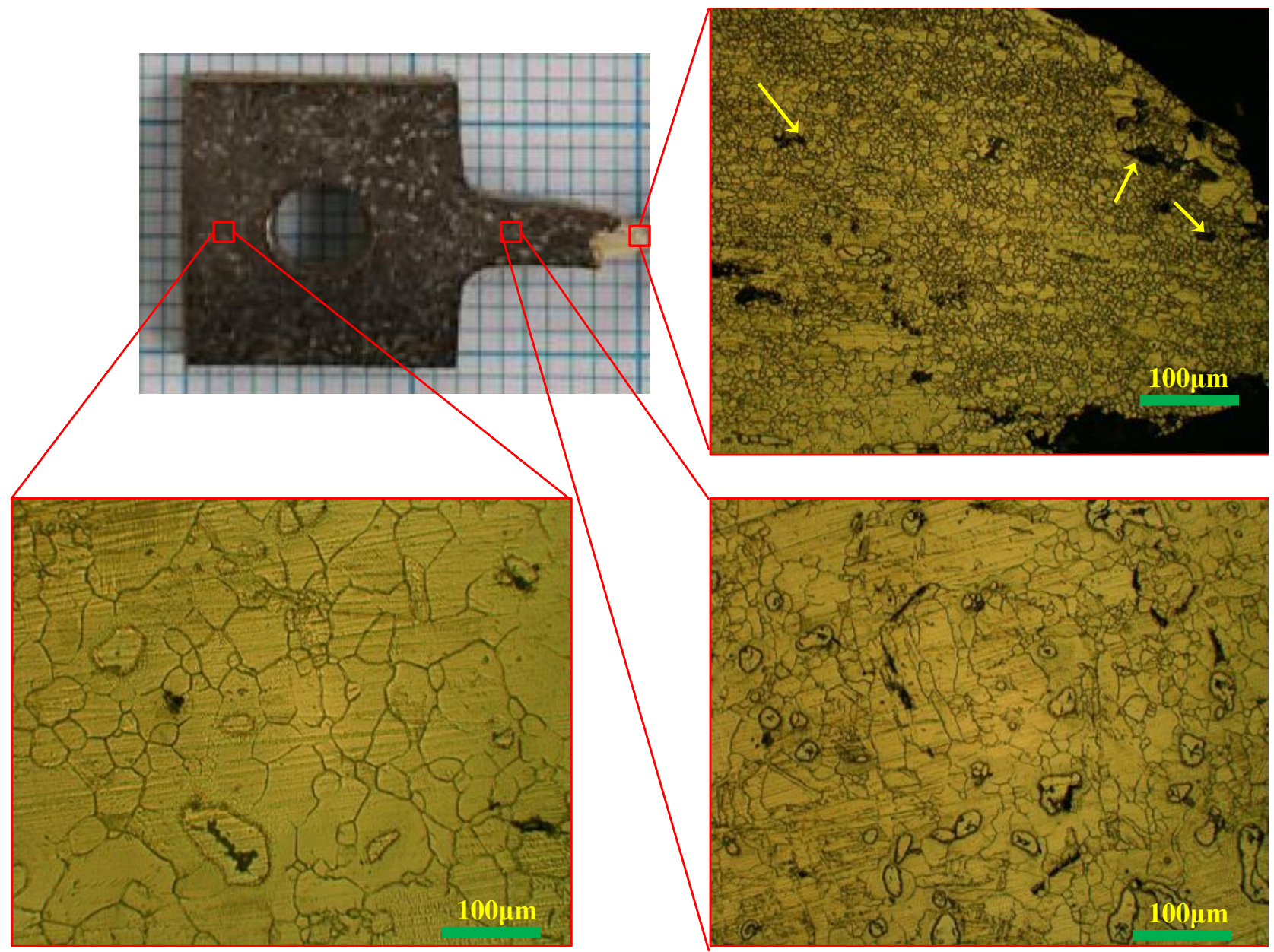

Fig. 7. The microstructure of the different positions of the fractured tensile test sample (prepared from two passes PTCAPed sample) deformed at $450{ }^{\circ} \mathrm{C}$. 


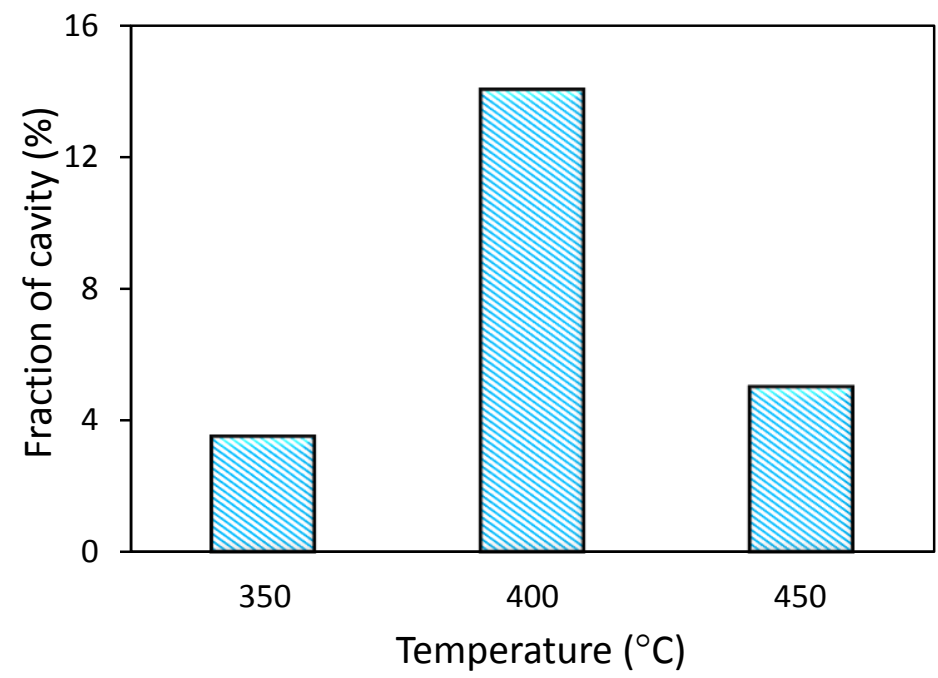

Fig. 8. The fraction of cavities at the fracture tip versus test temperature.

Fig. 9(a) shows the one-half of the fractured tensile sample (prepared from two passes PTCAPed sample) with tracking points ( $a$ to $i$ ) for evaluating the distribution of microstructure and mechanical properties. Fig. 9(b) represents the distribution of the grain size of the tracking points (points $a$ to $i$ ) at various test temperatures. From this figure, three distinguished results can be explained. First, a decreasing trend of grain size from positions $a$ to $i$ is evident in all samples. At position $i$, the enormous strain was applied, and dislocation accumulation besides DRX causes the formation of new finer grains. Second, the minimum average grain size belongs to the fracture tip region of the sample tested at $400{ }^{\circ} \mathrm{C}$. It is because of more imposing strain applied at this region during the tensile deformation and necking stage. Third, the different slopes of the curves were seen. It can be observed that required energy for grain growth is not supplied at 350 ${ }^{\circ} \mathrm{C}$. In contrast, at $450{ }^{\circ} \mathrm{C}$, the striking discrepancy appears between gripper region and the fracture tip. In the other word, noticeable grain growth takes place at $450{ }^{\circ} \mathrm{C}$ results from static annealing. 


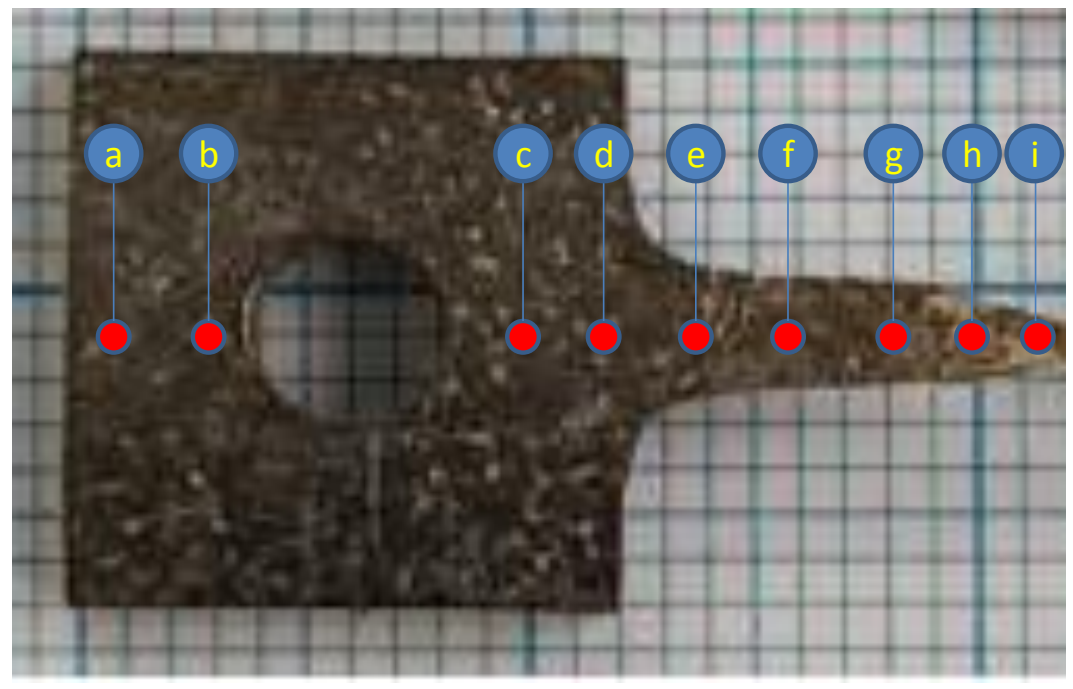

(a)

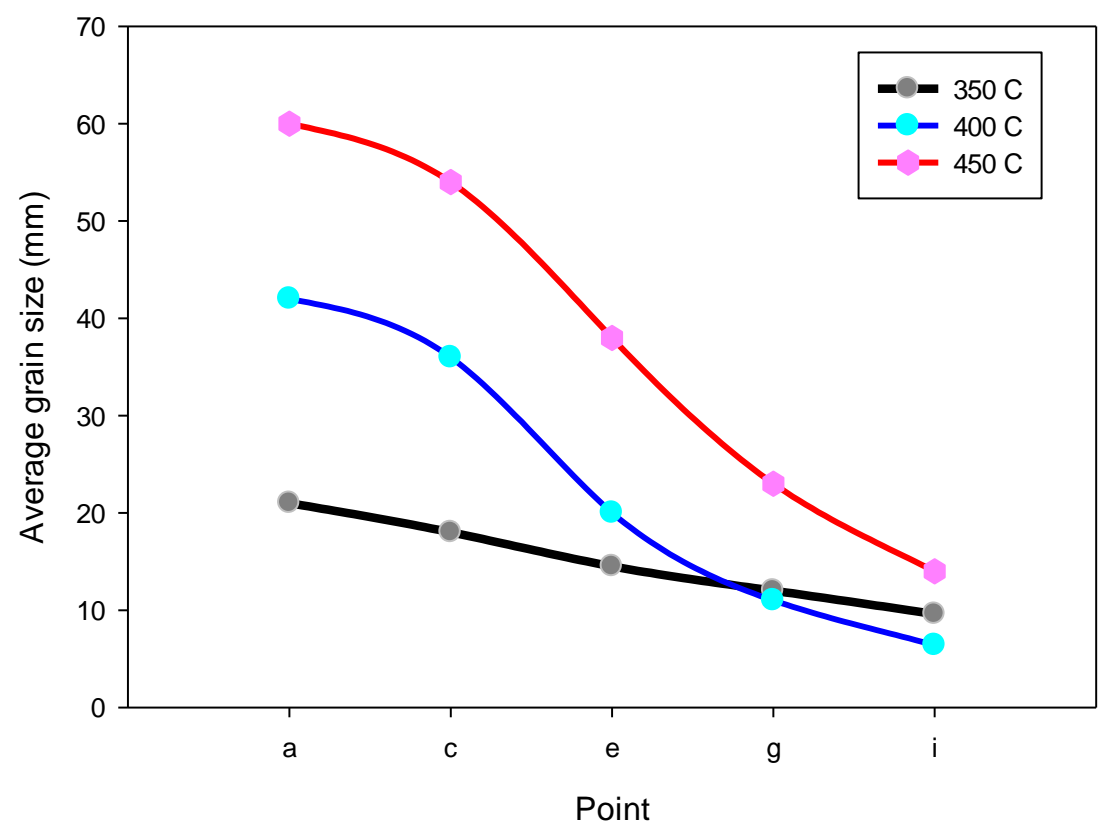

(b)

Fig. 9. (a) One-half of the fractured tensile sample (prepared from two passes PTCAPed sample) with tracking points (points $a$ to $i$ ) and (b) the distribution of the grain size in the tracking points (points $a$ to $i$ ) at various test temperatures. 
Fig. 10 shows the variation of hardness along the one-half of the fractured tensile samples along points $a$ to $i$ (as shown in Fig. 9(a)) at various temperatures. As the temperature increases, the hardness value decreases. At $450{ }^{\circ} \mathrm{C}$, grains growth is dominant, and consequently, hardness reduces in comparison to $350{ }^{\circ} \mathrm{C}$ and $400{ }^{\circ} \mathrm{C}$ cases. Clearly, in the gripper region, hardness remains almost unchanged but in the gauge length region, the hardness increases rapidly due to applying strain and more grain refinement. Meanwhile, the hardness in the fracture tip falls in all the curves of Fig. 10.

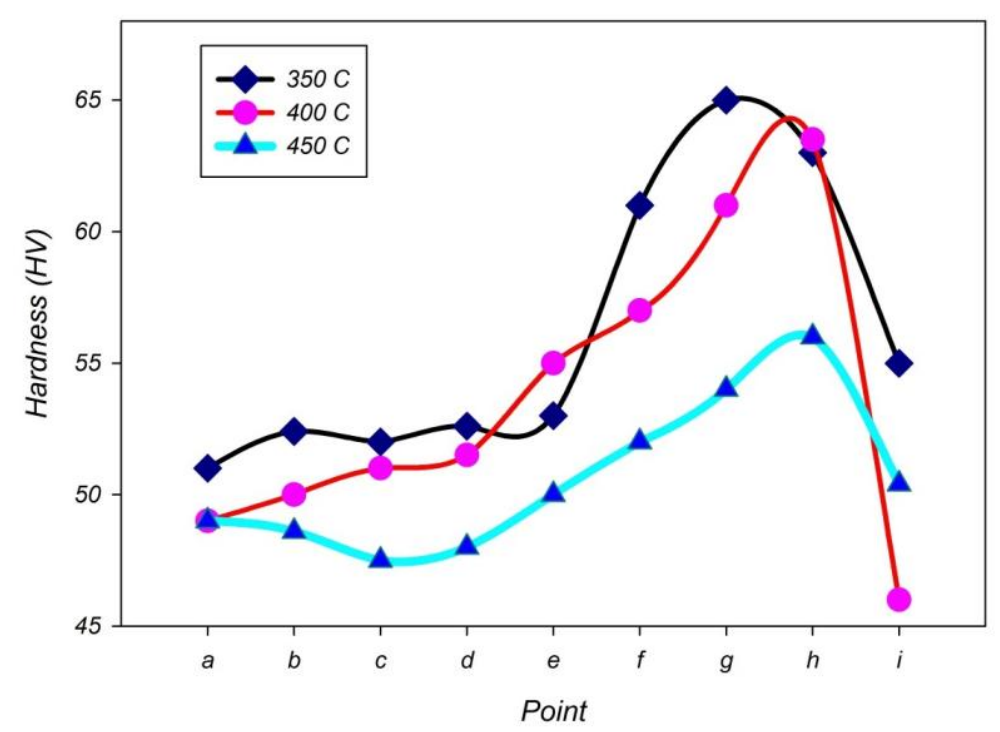

Fig. 10. Variations of hardness along the fractured tensile test sample.

Figs. 11 (a-c) shows SEM fractographic images of fractured surface of the tensile specimens (prepared from two passes PTCAPed sample) under the strain rate of $10^{-3} \mathrm{~s}^{-1}$ at various temperatures of $350{ }^{\circ} \mathrm{C}, 400{ }^{\circ} \mathrm{C}$, and $450{ }^{\circ} \mathrm{C}$. In general, localized cone-shaped necking region and macroscopic fracture with many microvoids can be found [26]. Fig. 11(a) shows that localized smooth neck with small dimples in the diversity of size and depth is seen. This indicates a combination of ductile and brittle fracture modes. Fig. 11(b) exhibits localized cone- 
shaped necking. The fractured surface consists of many small dimples and sharp tearing edge that indicates a specific characteristic of a ductile fracture mode. Moreover, at elevated temperatures, deformation mechanism of grain boundary sliding is activated. Therefore, the elongation to failure at $400{ }^{\circ} \mathrm{C}$ is $\sim 200 \%$ which is greater than that at $350{ }^{\circ} \mathrm{C}$. From Fig. 11 (c) a sharp localized necking with high reducing rate in the cross section could be seen.

\section{Discussion}

The bimodal microstructure of Figs. 2(b-d) appears when the unprocessed grain size is greater than a critical value [24]. Although further studies are now required for accurate quantifying of critical value, it depends on the alloy composition and processing temperature and also on the presence of a back-pressure or compressive hydrostatic pressure of the SPD method [25]. Grain boundaries as high energy regions are suitable for nucleation of new recrystallized grains as a result of the development of stress concentration and subsequent activation of basal and non-basal slip systems. Applying the further deformation up to third PTCAP pass (Fig. 2(d)) leads to a mix of equiaxed coarse and finer grains. This indicates a dynamic balance between the grain refinement by strain and grain growth occurred during PTCAP process of AZ31 at elevated temperatures. Thus, there exists a critical PTCAP pass number at a given temperature for obtaining a balance microstructure. Same phenomena were also reported in Ref. [32]. This observation confirms that the bimodal grain structure is transitional in nature and may be changed by imposing more strains.

As shown in Fig. 3, a softening behavior could be seen in all strain-stress curves. Softening behavior is more predominant as a consequence of the grain refinement by dynamic recrystallization and grain growth during the hot tensile testing [13]. During hot deformation, it 
was observed that the equiaxed shape and relatively small size of the grains remain unchanged after large elongations. Though, an additional strain enhanced the grain growth. It may be attributed to the fact that the grain neighbors change by relative grain translation results from grain boundary sliding $[33,34]$.

(a) $350{ }^{\circ} \mathrm{C}$

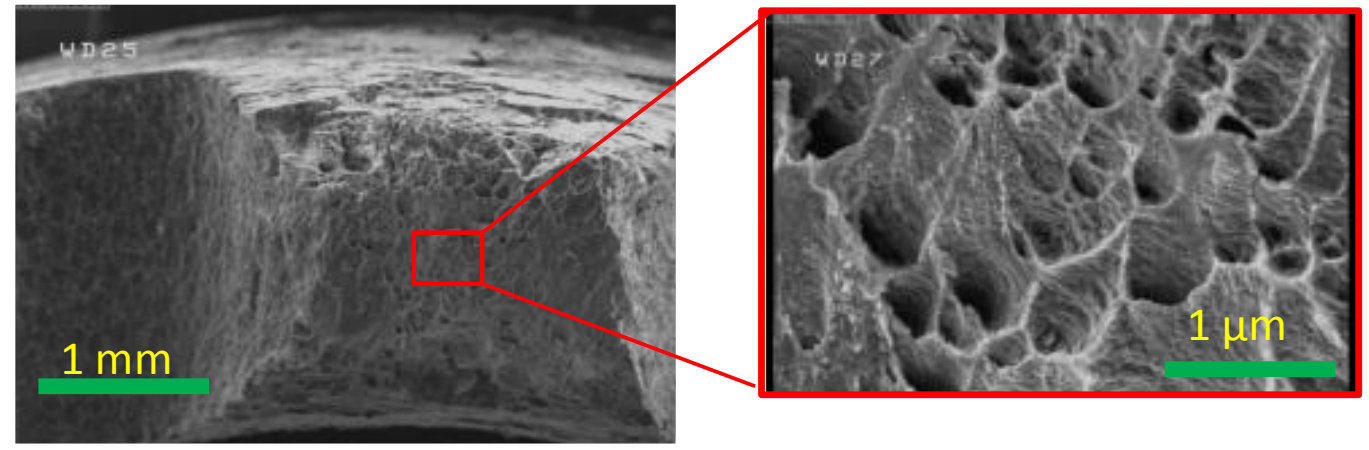

(b) $400{ }^{\circ} \mathrm{C}$

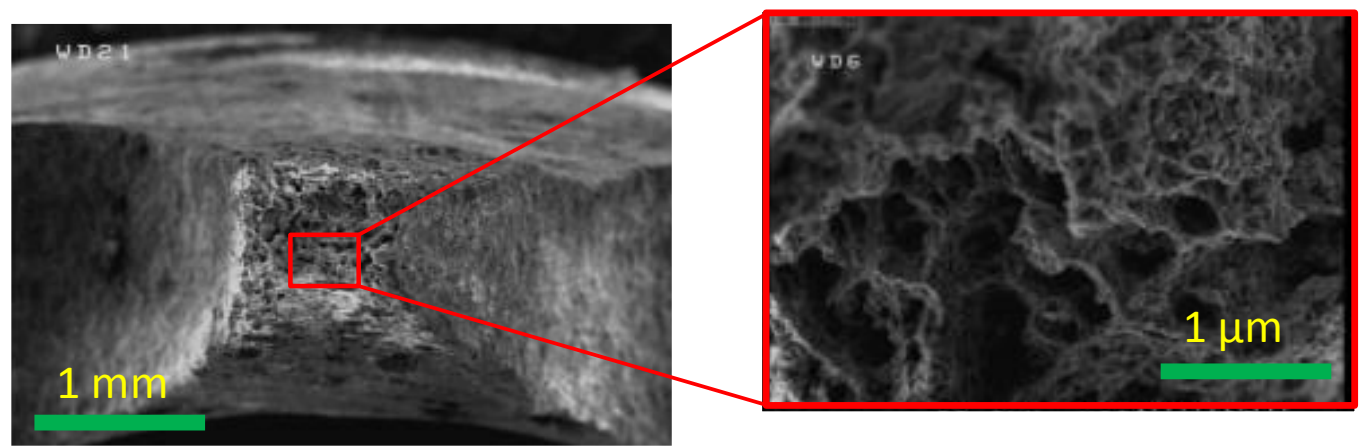

(c) $450{ }^{\circ} \mathrm{C}$

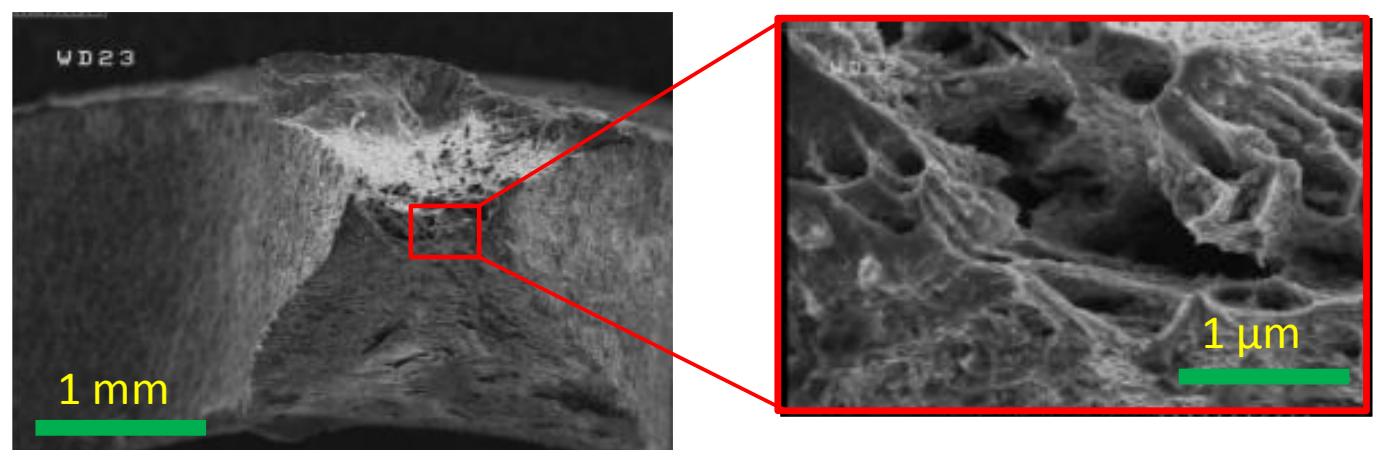

Fig. 11. SEM photomicrographs of the fractured surface of the tensile test sample at different temperatures. 
As observed in Fig. 4, the strength is decreased with increasing the test temperature. It is worth noting that the elongation at $400{ }^{\circ} \mathrm{C}$ is much greater in comparison with $450{ }^{\circ} \mathrm{C}$. This behavior can be considered as the result of two reasons. First, $450{ }^{\circ} \mathrm{C}$ is above the eutectic temperature $\left(\sim 430^{\circ} \mathrm{C}\right)$ [35], and inverse eutectic melting reaction $(\alpha+\beta=\mathrm{L})$ take place. It leads to the higher mobility of dislocation during plastic deformation. Second, DRX happened, and grain growth was perceived in the microstructure of the deformed sample. Table 2 compared published data on the high-temperature elongation of AZ31 magnesium alloy with the result of the current study.

Table 2. Summary of publications trying to achieve high ductility in AZ31.

\begin{tabular}{|c|c|c|c|c|c|c|c|}
\hline $\begin{array}{l}\text { AZ31 Initial } \\
\text { condition }\end{array}$ & $\begin{array}{l}\text { Initial } \\
\text { GS }(\mu m)\end{array}$ & Production method & $\begin{array}{l}\text { Final } \\
\text { GS }(\mu m)\end{array}$ & $\begin{array}{l}\text { Strain rate } \\
\left(s^{-1}\right)\end{array}$ & $\begin{array}{c}\text { Temperature } \\
\left({ }^{\circ} \mathrm{C}\right)\end{array}$ & $\begin{array}{l}\text { Elongation } \\
(\%)\end{array}$ & Ref. \\
\hline Extruded & 5.4 & ECAP, $8 \mathrm{P}\left(200^{\circ} \mathrm{C}\right)$ & 1 & $1 \times 10^{-3}$ & 200 & 200 & [36] \\
\hline Extruded & 35 & HPT, 10 turns , RT, 6 GPa & $110 \mathrm{~nm}$ & $1 \times 10^{-3}$ & 200 & 282 & [37] \\
\hline As-cast & 223 & $\mathrm{ECAP}, 5 \mathrm{P}\left(300^{\circ} \mathrm{C}\right)$ & 3.8 & $1 \times 10^{-2}$ & 350 & 156 & {$[38]$} \\
\hline Extruded & 9.4 & $\mathrm{ECAP}, 6 \mathrm{P}\left(200^{\circ} \mathrm{C}\right)$ & 1.6 & $3.3 \times 10^{-4}$ & 200 & 210 & {$[25]$} \\
\hline As-cast & - & $\begin{array}{l}\text { Extrusion } \quad\left(300 \quad{ }^{\circ} \mathrm{C} \quad\right) \\
+ \text { Rolling }\left(200^{\circ} \mathrm{C}\right),\end{array}$ & $500 \mathrm{~nm}$ & $5.0 \times 10^{-4}$ & 250 & 227 & [39] \\
\hline As-cast & 520 & $\operatorname{PTCAP}\left(300^{\circ} \mathrm{C}\right), 2 \mathrm{P}$ & 8 & $3 \times 10^{-3}$ & 350 & 79 & This study \\
\hline As-cast & 520 & $\operatorname{PTCAP}\left(300^{\circ} \mathrm{C}\right), 2 \mathrm{P}$ & 8 & $3 \times 10^{-3}$ & 400 & 263 & This study \\
\hline As-cast & 520 & $\operatorname{PTCAP}\left(300^{\circ} \mathrm{C}\right), 2 \mathrm{P}$ & 8 & $3 \times 10^{-3}$ & 450 & 145 & This study \\
\hline
\end{tabular}


It is evident that the elongation to failure depends on the grain size. AZ31 alloy with $110 \mathrm{~nm}$ grain size processed by HPT showed an elongation of about $282 \%$ [37] while the same alloy with one $\mu \mathrm{m}$ grain size processed by ECAP showed $200 \%$ elongation [36]. Also, it could be obviously seen that the temperature of the tensile testing has a significant effect on the elongation.

Plastic deformation during the hot tensile test mostly occurred in the grain growth step, whereas interlinkage is the main reason of the initiation of the failure. As shown in Fig. 6, during diffusional cavity formation mechanism, vacancies cluster together and form cavities via tensile stress after overcoming free-energy barrier [40]. These cavities could be seen in the fracture tip regions of all samples. Near the final fracture, flow stress apparently drops due to the cavitation effect. Before final fracture, the density of cavities and their size becomes larger. This leads to the cavity coalescence and intergranular separation. When the test temperature increased to 400 ${ }^{\circ} \mathrm{C}$ from $350{ }^{\circ} \mathrm{C}$, the grain size reaches to $\sim 6 \mu \mathrm{m}$. In the other word, the new grains easily generate with the increase of the temperature via DRX process at previously formed grain boundaries [41]. It can be concluded from Fig. 8, when the temperature changed from $350{ }^{\circ} \mathrm{C}$ to $400{ }^{\circ} \mathrm{C}$, the relative strain contribution at the grain boundaries increases. This assists the opening of voids in the grain boundaries. Nonetheless, at $450{ }^{\circ} \mathrm{C}$, the density of cavities is less than that in the $400{ }^{\circ} \mathrm{C}$. As is believed, increased diffusional accommodation at the higher temperatures is responsible for minimizing the strain concentration at the grain boundaries. Partly, elimination of some pre-existing defects during thermal stabilization can be responsible for this variation of cavities density [42].

The hardness of the fracture tip region falls in all curves of Fig. 10. This trend can be explained by this fact that the microvoids and cavities appeared during hot tensile deformation. Minimum hardness, as expected, was occurred in fracture tip of deformed sample at $400{ }^{\circ} \mathrm{C}$ that containing 
lots of cavities and microvoids during the period of hot deformation. As shown in Fig. 11, it is evident that at high-temperature deformation, grain boundary sliding is more active than dislocation slip. Therefore, ductility drops due to grain boundary sliding. Rapid grain growth at $450{ }^{\circ} \mathrm{C}$ causes to make the brittle fracture mode as dominant fracture mechanism [31]. Finally, the diffusional necking plays an important role in deformation process after yielding [26].

\section{Conclusion}

UFG AZ31 magnesium alloy tubes fabricated by PTCAP process through first, second and third passes and mechanical and microstructural evaluation during the hot tensile test were investigated at different temperatures. Following items could be concluded from this study:

- The bimodal structure appeared after PTCAP process because the initial grain size of 520 $\mu \mathrm{m}$ is larger than a critical value.

- The grain size was obviously affected by a number of PTCAP passes.

- The hot tensile tests revealed that second pass PTCAP processed sample exhibited 263\% elongation because grain boundary sliding is a dominant deformation mechanism at a temperature of $400{ }^{\circ} \mathrm{C}$.

- Nucleation was initiated from grain boundary at a temperature of $400{ }^{\circ} \mathrm{C}$, and a grain growth phenomenon happened at $450^{\circ} \mathrm{C}$.

- Analysis of the microstructure of the fractured tensile sample showed that lots of cavities were observed in fracture tip in all samples, largely at $400{ }^{\circ} \mathrm{C}$ temperature.

- The average grain size illustrated decreasing trend from gripper section to fracture tip. 
- Hardness dropped at failure tip because of presence considerable amount of cavities and microvoids.

- SEM photos of fractured surface illustrated the combination of ductile and brittle fracture at a temperature of $350{ }^{\circ} \mathrm{C}$.

- The fractured surface at $400{ }^{\circ} \mathrm{C}$ was revealed completely ductile fracture mode. However, with increasing the temperature to $450{ }^{\circ} \mathrm{C}$, fracture mode tends to be a mix of ductile and brittle.

\section{Acknowledgement}

This work was supported by Iranian National Science Foundation (INSF).

\section{References}

[1] B.L. Mordike, T. Ebert, Magnesium: Properties — applications — potential, Materials Science and Engineering: A, 302 (2001) 37-45.

[2] X.-w. Nie, S. Xie, H. Xu, Y. Du, Simulation of the ultra-fine microstructure evolution during annealing of AZ31 processed by ECAP, Physica B: Condensed Matter, 405 (2010) 1969-1972.

[3] A.S. Khan, A. Pandey, T. Gnäupel-Herold, R.K. Mishra, Mechanical response and texture evolution of AZ31 alloy at large strains for different strain rates and temperatures, International Journal of Plasticity, 27 (2011) 688-706.

[4] R.Z. Valiev, T.G. Langdon, Principles of equal-channel angular pressing as a processing tool for grain refinement, Progress in Materials Science, 51 (2006) 881-981.

[5] W.J. Kim, S.I. Hong, Y.S. Kim, S.H. Min, H.T. Jeong, J.D. Lee, Texture development and its effect on mechanical properties of an AZ61 Mg alloy fabricated by equal channel angular pressing, Acta Materialia, 51 (2003) 3293-3307.

[6] Y. Iwahashi, J. Wang, Z. Horita, M. Nemoto, T.G. Langdon, Principle of equal-channel angular pressing for the processing of ultra-fine grained materials, Scripta Materialia, 35 (1996) 143-146. 
[7] C. Xu, Z. Horita, T.G. Langdon, The evolution of homogeneity in processing by high-pressure torsion, Acta Materialia, 55 (2007) 203-212.

[8] A. Loucif, R.B. Figueiredo, T. Baudin, F. Brisset, T.G. Langdon, Microstructural evolution in an Al6061 alloy processed by high-pressure torsion, Materials Science and Engineering: A, 527 (2010) 48644869.

[9] M. Das, G. Das, M. Ghosh, M. Wegner, V. Rajnikant, S. GhoshChowdhury, T.K. Pal, Microstructures and mechanical properties of HPT processed 6063 Al alloy, Materials Science and Engineering: A, 558 (2012) 525-532.

[10] Y. Saito, H. Utsunomiya, N. Tsuji, T. Sakai, Novel ultra-high straining process for bulk materialsdevelopment of the accumulative roll-bonding (ARB) process, Acta Materialia, 47 (1999) 579-583.

[11] N. Tsuji, Y. Saito, S.H. Lee, Y. Minamino, ARB (Accumulative Roll-Bonding) and other new Techniques to Produce Bulk Ultrafine Grained Materials, Advanced Engineering Materials, 5 (2003) 338344.

[12] H. Pirgazi, A. Akbarzadeh, R. Petrov, L. Kestens, Microstructure evolution and mechanical properties of AA1100 aluminum sheet processed by accumulative roll bonding, Materials Science and Engineering: A, 497 (2008) 132-138.

[13] S.H. Kang, Y.S. Lee, J.H. Lee, Effect of grain refinement of magnesium alloy AZ31 by severe plastic deformation on material characteristics, Journal of Materials Processing Technology, 201 (2008) 436-440.

[14] Y. Miyahara, Z. Horita, T.G. Langdon, Exceptional superplasticity in an AZ61 magnesium alloy processed by extrusion and ECAP, Materials Science and Engineering: A, 420 (2006) 240-244.

[15] G. Faraji, A. Babaei, M.M. Mashhadi, K. Abrinia, Parallel tubular channel angular pressing (PTCAP) as a new severe plastic deformation method for cylindrical tubes, Materials Letters, 77 (2012) $82-85$.

[16] G. Faraji, M. Mashhadi, A. Bushroa, A. Babaei, TEM analysis and determination of dislocation densities in nanostructured copper tube produced via parallel tubular channel angular pressing process, Materials Science and Engineering: A, 563 (2013) 193-198.

[17] V. Tavakkoli, M. Afrasiab, G. Faraji, M.M. Mashhadi, Severe mechanical anisotropy of highstrength ultrafine grained $\mathrm{Cu}-\mathrm{Zn}$ tubes processed by parallel tubular channel angular pressing (PTCAP), Materials Science and Engineering: A, 625 (2015) 50-55.

[18] G. Faraji, M.M. Mashhadi, A.R. Bushroa, A. Babaei, TEM analysis and determination of dislocation densities in nanostructured copper tube produced via parallel tubular channel angular pressing process, Materials Science and Engineering: A, 563 (2013) 193-198. 
[19] M. Afrasiab, G. Faraji, V. Tavakkoli, M.M. Mashhadi, A.R. Bushroa, Excellent energy absorption capacity of nanostructured $\mathrm{Cu}-\mathrm{Zn}$ thin-walled tube, Materials Science and Engineering: A, 599 (2014) 141-144.

[20] G. Faraji, P. Yavari, S. Aghdamifar, M.M. Mashhadi, Mechanical and Microstructural Properties of Ultra-fine Grained AZ91 Magnesium Alloy Tubes Processed via Multi Pass Tubular Channel Angular Pressing (TCAP), Journal of Materials Science \& Technology, 30 (2014) 134-138.

[21] M. Afrasiab, G. Faraji, V. Tavakkoli, M.M. Mashhadi, K. Dehghani, The Effects of the Multi-pass Parallel Tubular Channel Angular Pressing on the Microstructure and Mechanical Properties of the $\mathrm{Cu}-$ Zn Tubes, Transactions of the Indian Institute of Metals, 68 (2015) 873-879.

[22] K. Bryª a, J. Dutkiewicz, P. Malczewski, Grain refinement in AZ31 alloy processed by equal channel angular pressing, Archives of Materials Science, 18 (2009) 18.

[23] R.B. Figueiredo, T.G. Langdon, Principles of grain refinement and superplastic flow in magnesium alloys processed by ECAP, Materials Science and Engineering: A, 501 (2009) 105-114.

[24] R.B. Figueiredo, T.G. Langdon, Developing superplasticity in a magnesium AZ31 alloy by ECAP, J Mater Sci, 43 (2008) 7366-7371.

[25] R.B. Figueiredo, T.G. Langdon, Grain refinement and mechanical behavior of a magnesium alloy processed by ECAP, J Mater Sci, 45 (2010) 4827-4836.

[26] J. Deng, Y.C. Lin, S.-S. Li, J. Chen, Y. Ding, Hot tensile deformation and fracture behaviors of AZ31 magnesium alloy, Materials \& Design, 49 (2013) 209-219.

[27] W.P. Peng, P.J. Li, P. Zeng, L.P. Lei, Hot deformation behavior and microstructure evolution of twin-roll-cast Mg-2.9Al-0.9Zn alloy: A study with processing map, Materials Science and Engineering: A, 494 (2008) 173-178.

[28] O. Sabokpa, A. Zarei-Hanzaki, H.R. Abedi, An investigation into the hot ductility behavior of AZ81 magnesium alloy, Materials Science and Engineering: A, 550 (2012) 31-38.

[29] A.H. Chokshi, T.G. Langdon, A model for diffusional cavity growth in superplasticity, Acta Metallurgica, 35 (1987) 1089-1101.

[30] A.H. Chokshi, The development of cavity growth maps for superplastic materials, Journal of Materials Science, 21 2073-2082.

[31] P.S. Roodposhti, A. Sarkar, K.L. Murty, Fracture Behavior of AZ31 Magnesium Alloy During LowStress High-Temperature Deformation, Metallography, Microstructure, and Analysis, 4 (2015) 91-101.

[32] Y. Chen, Q. Wang, J. Peng, C. Zhai, W. Ding, Effects of extrusion ratio on the microstructure and mechanical properties of AZ31 Mg alloy, Journal of Materials Processing Technology, 182 (2007) 281285. 
[33] T.H. Alden, The origin of superplasticity in the sn-5\%bi alloy, Acta Metallurgica, 15 (1967) 469480.

[34] J. Koike, T. Kobayashi, T. Mukai, H. Watanabe, M. Suzuki, K. Maruyama, K. Higashi, The activity of non-basal slip systems and dynamic recovery at room temperature in fine-grained AZ31B magnesium alloys, Acta Materialia, 51 (2003) 2055-2065.

[35] S.-W. Lee, Y.-L. Chen, H.-Y. Wang, C.-F. Yang, J.-W. Yeh, On mechanical properties and superplasticity of $\mathrm{Mg}-15 \mathrm{Al}-1 \mathrm{Zn}$ alloys processed by reciprocating extrusion, Materials Science and Engineering: A, 464 (2007) 76-84.

[36] J. Xu, M. Shirooyeh, J. Wongsa-Ngam, D. Shan, B. Guo, T.G. Langdon, Hardness homogeneity and micro-tensile behavior in a magnesium AZ31 alloy processed by equal-channel angular pressing, Materials Science and Engineering: A, 586 (2013) 108-114.

[37] J. Xu, X. Wang, M. Shirooyeh, G. Xing, D. Shan, B. Guo, T.G. Langdon, Microhardness, microstructure and tensile behavior of an AZ31 magnesium alloy processed by high-pressure torsion, Journal of Materials Science, 50 (2015) 7424-7436.

[38] S. Kang, Y. Lee, J. Lee, Effect of grain refinement of magnesium alloy AZ31 by severe plastic deformation on material characteristics, Journal of Materials Processing Technology, 201 (2008) 436-440. [39] X. Wang, M. Wu, W. Ma, Y. Lu, S. Yuan, Achieving Superplasticity in AZ31 Magnesium Alloy Processed by Hot Extrusion and Rolling, Journal of Materials Engineering and Performance, 25 (2016) 64-67.

[40] R. Raj, Nucleation of cavities at second phase particles in grain boundaries, Acta Metallurgica, 26 (1978) 995-1006.

[41] S. Spigarelli, M. El Mehtedi, Creep as an extension of hot working: A unified approach to high temperature deformation of AZ31 alloy, Materials Science and Engineering: A, 527 (2010) 5708-5714.

[42] D.H. Bae, A.K. Ghosh, Cavity formation and early growth in a superplastic Al-Mg alloy, Acta Materialia, 50 (2002) 511-523. 


\section{Figure captions}

Fig. 1. Schematic of (a) first half pass and (b) second half pass of the PTCAP process with the die parameters [21].

Fig. 2. OM microstructure of as received (a), and PTCAP processed tube through first (b), second (c), and third (d) passes.

Fig. 3. Engineering stress-strain curves of as received and multipass PTCAP processed samples tested at $400{ }^{\circ} \mathrm{C}$ at an initial strain rate of $0.001 \mathrm{~s}^{-1}$.

Fig. 4. Engineering stress-strain curves of second pass PTCAP processed at different temperatures at a strain rate of $0.001 \mathrm{~s}^{-1}$.

Fig. 5. OM microstructure of the various positions of the fractured tensile test sample (prepared from two passes PTCAPed sample) deformed at $350^{\circ} \mathrm{C}$.

Fig. 6. The microstructure of various positions of the fractured tensile test sample (prepared from two passes PTCAPed sample) deformed at $400{ }^{\circ} \mathrm{C}$.

Fig. 7. The microstructure of the different positions of the fractured tensile test sample (prepared from two passes PTCAPed sample) deformed at $450^{\circ} \mathrm{C}$.

Fig. 8. The fraction of cavities at the fracture tip versus test temperature.

Fig. 9. (a) One-half of the fractured tensile sample (prepared from two passes PTCAPed sample) with tracking points (points $a$ to $i$ ) and (b) the distribution of the grain size in the tracking points (points $a$ to $i$ ) at various test temperatures.

Fig. 10. Variations of hardness along the fractured tensile test sample.

Fig. 11. SEM photomicrographs of the fractured surface of the tensile test sample at different temperatures. 


\section{Table captions}

Table 1. The chemical composition of AZ31 magnesium.

Table 2. Summary of publications trying to achieve high ductility in AZ31. 